\title{
Sustained Impact of Professional Enhancement Program of National Academy of Higher Education in Pakistan
}

\author{
Dr. Shafqat Hussain \\ Department of Education, GC University Faisalabad, Pakistan \\ Tel: 92-300-771-1441_E-mail: drhssn@yahoo.com \\ Dr. Muhammad Sarwar (Corresponding author) \\ Department of Education, University of Sargodha, Sargodha, Pakistan \\ Tel: 92-321-860-0055Ｅ-mail: drsarwar@ymail.com \\ Dr. Haq Nawaz Anwar \\ Department of Sociology, GC University Faisalabad, Pakistan \\ E-mail: hnanwar@yahoo.com
}

\begin{abstract}
The present study was designed to assess the sustained impact of National Academy of Higher Education (NAHE)'s Staff Development Course after a period of two years. All the teachers of public sector universities/institutions, who attended one-month staff development course, constituted the population of the study. The sample consisted of 116 participants of the one of the course from the University of Sargodha and GC University Faisalabad. The data were collected in 2009. The researchers administered the first sixteen items of the questionnaire used by Hussain (2007) for the impact analysis study of the NAHE Staff Development Programs. The data were compared to see the sustained impact on simple percentage basis of the responses. The study explored, after two years of the course the teaching-learning skills of the participants were not only sustained but also enhanced with the passage of time.
\end{abstract}

Keywords: Impact, Higher education, Sustained, Faculty development, Pakistan

\section{Introduction}

Higher education is of paramount importance for economic and social development (Khan, 2005). In developing countries, higher education is seen as an essential means for the creation and development of resources and for improving the life of people to whom it has to serve (Wickrama, 1996).

Staff development is the sum of activities that enhance the knowledge, skills, performance, vision and understanding of the staff. In educational institutions, staff development programme improves the communication skills, classroom behaviour, teaching methods and thinking of the teacher. The purpose of staff development is to promote the quality of pupils' learning by different teaching strategies. Education is a process to give intellectual, moral, and social instruction especially as a formal prolonged process, which includes training or instruction for a particular purpose. It includes development of character and mental power through systematic instruction (Anjum, 1998).

On-going professional development of the university staff should be conducted because it cultivates those skills whose application will improve the efficiency and effectiveness with which the anticipated results of a particular organizational segment are achieved. Staff development is the planned influence on an individual's knowledge, and its purpose is to gain the individual's commitment to the philosophies, values and goals of a particular organization (Main, 1985). Sisodia (2000) says that the success of any organization largely depends on the effectiveness of its management, which in turn is principally determined by the vision, skill, and experience of its staff.

Teachers who entered the profession years back or those who enter today cannot do justice to their job unless they continue to grow or to update the content as well as the techniques of teaching. Education has made tremendous progress in terms of all that it is concerned with; even the meaning of the word education is no 
longer what it was. From the learning of three years, it has traversed to the total development of mean. From teaching of subjects alone it has extended to help the child grow in all aspects that constitute its personality. The tools of education such as courses, books, examinations and teaching techniques have also undergone several changes. Therefore, the teacher who is to impart education and who has to negotiate the tools of education must grow and equip himself with all that is needed to meet the expectations of the present day educational set up (Kakkar, 1996). The expansion in higher education needs adequately qualified and properly trained teachers to maintain the higher education institutions (UGC, 1983a).

NAHE has been striving hard since 2004 to conduct professional development training courses for the enhancement of teaching competencies of university teachers at their door step. In Phase-I NAHE imparted training to 3564 university teachers in 38 Human Resource Development Centers established at the public sector universities of Pakistan. NAHE conducts these training courses through its key component named as "Professional Competency Enhancement Program for University Teachers" (PCEPT). It is a 24 days program (http://www.hec.gov.pk/InsideHEC/Divisions/QALI/NAHE/Pages/PCEPT.aspx)

The present study was designed to assess the sustained impact of the NAHE Staff Development Courses on the teaching staff of public sector universities/institutions. Data were collected from a sample of trainees to see the sustained impact.

\section{Objectives of the Study}

The specific objectives of the study were to assess the sustained impact of NAHE's Staff Development Course after a period of two years on the sixteen teaching-learning skills mentioned in table 1, and to suggest some measures to keep up the National Academy of Higher Education Staff Development Programme for better future of Higher Education in Pakistan.

\section{Methodology}

All the teachers of public sector universities/institutions who attended one-month staff development course, constituted the population of the study. The researchers used the first sixteen items of the same questionnaire that were used for the impact analysis study of the National Academy of Higher Education Staff Development Programme two years ago (Hussain, 2007). Data was collected from a sample consisted of 116 participants of the one month Staff Development Course of National Academy of Higher Education from the University of Sargodha and GC University Faisalabad. One of the researchers personally visited both the Universities and collected required data. Data collected were compared to see the sustained impact on simple percentage basis of the responses.

\section{Findings and Discussion}

Since the researchers were interested to investigate the sustained impact of the National Academy of Higher Education's Staff Development Programme, to serve the purpose, researchers compared the strongly agree and agree responses of the participants on all the statements.

The above table indicates that sixteen skills, which were the focus of the staff Development Programme, are not only sustained but are increased with passage of time, one of the reason may be the increased teaching experience of the teachers along with the increased knowledge of these skills due to National Academy of Higher Education' Staff Development Programme, except the skill of using teaching aids (on strongly agree response) but coincidently there is increase of $21 \%$ in the agree responses of the respondents. It is interesting to describe that two skills (content knowledge about research skills and ability to develop research proposal) are only sustained and didn't increase. The reason for this may be the less promoted research culture in the universities of Pakistan.

On the whole if we see the overall increase of 11 percent on the use and competency of sixteen teaching skills, shows the sustainability of the staff development course. Again the reason for increase in total percentage may the increased experience of the participants, there may be another reasons the same teachers may have studied some new material on these teaching skills and they did practice of it.

Studies on teacher education in Pakistan have identified the following problems in in-service training: viewing training and teaching as separate and unconnected activities; viewing learning as book learning to prepare for examinations rather than an on-going, life-long process, and not seeing their own practice as a source of learning; lack of time to apply training; lack of understanding of group work; difficulty in transferring generic teaching skills from one subject to another; officials viewing group work and interactive teaching methods as lacking in discipline (Jaffer, 1998a; Jaffer and Hughes-d' Aeth, 1998; Jaffer, Hussain et al, 2004; Hussain and Abbasi, 1995; Nauman, 1995; Qureshi and Rahmatullah, 2000; Saleemi, 1999; Siddiqui, 1997; Smith et al, 1988; Van Kalmthout and O'Grady, 1992; Warwick and Reimers, 1990, 1991). 
A review of in-service teacher training methods identified a number of effective and innovative training models in Pakistan in the private sector to improve teacher quality (Jaffer, 1998b). The Aga Khan University Institute for Educational Development provides high quality in-service training for teachers through Professional Development Centres which involves a close link between teaching, training and research. A long-term training program of the Aga Khan Education Service, which combined classroom observations with daily reviews, was very effective in improving teacher content knowledge and classroom practices (Bude and Chowdhri, 1989; Bude, 1992; Chowdhri and Abbas, 1987).

In one study involving training of Instructors of the Regional Institutes of Teacher Education comparison of pre and post test scores showed an average increase of $36 \%$ in pedagogical skills and $34 \%$ in subject skills (Jaffer, Hussain et al, 2005)

On the other hand an evaluation of the Training and Resource Centres (TARCs) of the Ali Institute of Education (AIE) produced mixed results. While training improved teaching skills like providing feedback to pupils, encouraging positive behaviour, using AV aids appropriately, conducting activities, and creating a pleasant environment for learning, teaching was generally teacher-centred, with few questions by pupils, and most teachers did not use lesson plans, review previous lesson or link it to the present lesson, state topic and lesson objectives, or summarize lesson. (Jaffer, Hussain et al, 2004).

\section{Suggestions}

On the basis of the findings and discussion, following suggestions were made:

1. In-service Staff Development Courses should be arranged periodically by Higher Education Commission or by any other authority to introduce latest techniques of teaching and research for all university teachers.

2. Such type of Staff Development Courses must be compulsory for newly inducted teachers in the institutions of Higher Education.

3. Genuine research culture must be promoted in the institutions of Higher Education.

\section{References}

Anjum, G. H. (1998). Education \& the challengers of $21^{\text {st }}$ Century. Lahore: Pakistan Education Forum.

Bude, U. (1992). Field-Based Teacher Development Programme: A Monitoring Exercise in Chitral, Northwest Frontier Province, and a Review of FBTD Activities in the Northern Areas of Pakistan. German Foundation for International Development, Bonn.

Bude, U., \& Chowdhri, S. (1989). Improving Primary School Teaching: An Evaluation of the Field-Based Teacher Development Programme in the Northern Areas of Pakistan. German Foundation for International Development, Bonn.

Chowdhri, S., \& Abbas, S. (1987). Evaluation of Field-Based Teachers Training Programme in the Northern Areas of Pakistan. National Institute of Psychology, Islamabad.

Hussein, A. K., \& Abbasi, M.H. (1995). Teacher Education in Primary Education Projects: A Review. Islamabad, March.

Hussain, S. (2007). Impact analysis of NAHE'S faculty development programme. Unpublished Report. Islamabad: Higher Education Commission.

Jaffer, R. (1998). Putting the Child First: Teacher Education for Quality Learning and School Improvement. Pakistan-Canada Social Institutions Development Programme, Aga Khan Foundation, and Canadian International Development Agency, Islamabad.

Jaffer, R. \& Aeth, A. H. (1998). Teacher Education \& Training in NWFP - Institutional Review and Strategic Plan. GTZ/PEPCO/PEP-ILE, Peshawer.

Jaffer, R., Hussain, S., Jaffer, R., Kazmi, M., Yasin, M., Hamid, A. \& Hamid, R. (2004). Education through Superlearning - Pilot Testing in Primary and NFE Schools of Kasur, Sheikhupura, Gujranwala and Sialkot Districts. Sudhaar.

Jaffer, R., Hussain, S., Jaffer, R., Kazmi, M., Yasin, M., \& Abbas, R. Z. (2005). Strengthening Provincial and Regional Institutes of Teacher Education, NWFP, Report of Technical Assistance to Basic Education Improvement Project (BEIP).

Khan, M.N. (2005). Designing a model for staff development for higher education in Pakistan. Unpublished PhD thesis. Rawalpindi. University of Arid agriculture

Main, A. (1985). Educational Staff Development. Sydney: Croom Helm. 
Nauman, H. (1995). Improving the Impact of Primary School Teacher Training on Schooling Effectiveness. MSU, Lahore.

Qureshi, M.A., \& Rahmatullah, C. (2000). Improving Training Strategies: Piloting Demand-led Training in the Punjab. PMSP Research and Evaluation Series, No. 9.

Saleemi, F. (1999). Factors Affecting Development of Female Education in Punjab, Issues and Problems in Development of Female teacher education and Their Retention in the Teaching Profession. Directorate of Staff Development.

Shah, M.H. (2002). The Impact of PEP-ILE Inputs on Children Achievement and Teacher Behaviour. Peshawar: PEP-GTZ.

Siddiqui, S.A. (1997). Teacher Education at the Middle Stage Level: Problems and Prospects. Madecor Career Systems, Islamabad, July.

Sisodia, M. L. (2000). Higher Education Growth and Future Options. Jaipur, India: University Book House.

Smith, R. L. Hough, J.R., \& Thomson, M. (1988). Underwood Pakistan Teacher Training Survey. The British Council, Islamabad.

University Grants Commission. (1983). An Introduction to University Grants Commission. Islamabad: University Grants Commission.

Van, K. E. \& Grady, B. (1992). Teacher Training/Teacher Content Knowledge Study. Forum for Advancing Basic Education and Literacy. HIID.

Warwick, D.P. \& Fernando, M. R. (1990). Teacher Certification: Value Added or Money Wasted. BRIDGES Research Report Series, HIID.

Warwick, D. P. \& Fernando, M. R. (1991). Good Schools and Poor Schools in Pakistan. Development Discussion Paper No. 399 ES. HIID,

Wickrama, B. A. (1996). Higher Education in Ceylon. UNESCO Bulletin, 9(1).

Table 1. Showing the sustained impact on teaching learning sixteen skills

\begin{tabular}{|c|c|c|c|c|c|c|c|c|c|c|c|}
\hline \multirow{2}{*}{$\begin{array}{l}\text { Sr. } \\
\text { No. }\end{array}$} & \multirow{2}{*}{$\begin{array}{l}\text { This training/course had } \\
\text { improved/developed my following skills or } \\
\text { abilities etc. }\end{array}$} & \multicolumn{2}{|c|}{ SA } & \multicolumn{2}{|c|}{$\mathbf{A}$} & \multicolumn{2}{|c|}{$\mathbf{U}$} & \multicolumn{2}{|c|}{ D } & \multicolumn{2}{|c|}{ SD } \\
\hline & & $\begin{array}{l}\text { Po } \\
\%\end{array}$ & $\begin{array}{l}\text { Pre } \\
\%\end{array}$ & $\begin{array}{l}\text { Po } \\
\%\end{array}$ & $\begin{array}{l}\text { Pre } \\
\%\end{array}$ & $\begin{array}{l}\text { Po } \\
\%\end{array}$ & $\begin{array}{l}\text { Pre } \\
\%\end{array}$ & $\begin{array}{l}\text { Po } \\
\%\end{array}$ & $\begin{array}{l}\text { Pre } \\
\%\end{array}$ & $\begin{array}{l}\text { Po } \\
\%\end{array}$ & $\begin{array}{l}\text { Pre } \\
\%\end{array}$ \\
\hline 1 & Confidence in teaching & 66 & 43 & 34 & 51 & 00 & 03 & 00 & 03 & 00 & 00 \\
\hline 2 & Knowledge of individual differences & 45 & 21 & 05 & 65 & 03 & 12 & 00 & 01 & 00 & 01 \\
\hline 3 & $\begin{array}{l}\text { Content knowledge about educational } \\
\text { psychology }\end{array}$ & 45 & 31 & 41 & 52 & 03 & 12 & 11 & 03 & 00 & 02 \\
\hline 4 & Teaching skills/style & 52 & 39 & 45 & 50 & 03 & 07 & 00 & 02 & 00 & 02 \\
\hline 5 & Interaction with students & 66 & 41 & 28 & 46 & 03 & 07 & 03 & 05 & 00 & 01 \\
\hline 6 & Lesson planning & 38 & 27 & 62 & 55 & 00 & 12 & 00 & 04 & 00 & 02 \\
\hline 7 & To adopt innovations in teaching & 52 & 35 & 38 & 46 & 07 & 14 & 03 & 04 & 00 & 01 \\
\hline 8 & Use of teaching aids & 24 & 41 & 62 & 41 & 07 & 14 & 07 & 03 & 00 & 01 \\
\hline 9 & Communication skills & 52 & 42 & 48 & 46 & 00 & 09 & 00 & 02 & 00 & 01 \\
\hline 10 & Classroom management skills & 45 & 26 & 41 & 40 & 03 & 30 & 03 & 03 & 08 & 01 \\
\hline 11 & Problems solving skills & 42 & 25 & 55 & 41 & 03 & 27 & 00 & 05 & 00 & 02 \\
\hline 12 & Content knowledge about research skills & 23 & 23 & 41 & 41 & 29 & 29 & 06 & 06 & 01 & 01 \\
\hline 13 & To develop a research proposal & 20 & 20 & 42 & 42 & 27 & 27 & 08 & 08 & 03 & 03 \\
\hline 14 & Ability to write a report & 38 & 25 & 35 & 41 & 17 & 24 & 03 & 07 & 07 & 03 \\
\hline 15 & Ability to develop subjective type test & 48 & 25 & 45 & 44 & 04 & 24 & 03 & 06 & 00 & 01 \\
\hline 16 & Ability to develop objective type test & 55 & 29 & 42 & 44 & 03 & 21 & 00 & 05 & 00 & 01 \\
\hline 17 & Total mean percentage & 45 & 31 & 43 & 46 & 07 & 17 & 03 & 04 & 01 & 01 \\
\hline
\end{tabular}

